\title{
A year of perseverance for a research team
}

\author{
Tam-Tri Le \\ Centre for Interdisciplinary Social Research \\ Phenikaa University, Hanoi, Vietnam
}

Written in Ho Chi Minh City on 24 October 2021

In the human eye, the world can be beautiful, and it can also be ugly. But when the world seems ugly, we do not have to be.

This year 2021, humanity is still deep in the crisis of the COVID-19 pandemic. My country Vietnam has been facing a big wave of infection which has disrupted our society and taken away more than 20000 lives so far. The pandemic and all it brought is a heavy shadow pressing on people's minds, withering their mental health [1]. On the horizon, the silhouette of a grim future for the Earth's natural environment is continuing to fall into shape [2]. Inside the harsh storm of reality, people may come to realize that humans are strong from knowing how weak they are (in order to keep moving forward).

As for my personal journey, this year I started working with my mentor and colleagues at the Centre for Interdisciplinary Social Research (ISR - Vietnam). It has been a great opportunity for me on the path of science. To firmly walk on the road to a brighter tomorrow, my team follows three main principles in thinking and working in the academic fields. Personally, I would like to present these principles in relation to my general view on human existence: resources are limited so we need to appreciate and use them wisely [3]; the world is constantly changing so we need to aim for the best and prepare for the worst [4]; morality is the base for creating good values [5].

As scientists, we try to fight for a better future with sharp tools and a passionate spirit. Regarding the tool aspect, our team developed the scientific methodologies for our works based on mathematical foundations [6,7], created technically validated methods and protocols [8,9]; and this year, we continued to publish several open datasets on different disciplines $[10,11,12,13]$ as well as continued to expand the Bayesian Mindsponge Framework [14]. Regarding the spirit aspect, this year our team has published some articles that I personally find to be particularly memorable and socially impactful: the mechanism of suicidal ideation [15], the mechanism of suicide attack and implications for effective peacemaking [16], the semiconducting principle of monetary and environmental values exchange [17].

This year, many scientists have been working hard for the sake of human advancement despite the rather challenging global situation. I humbly believe that by knowing how to use the natural superpower of curiosity and creativity with a pure heart, humanity will be able to find beauty even in those moments when the world seems to be against us. 


\section{References}

1. Kumar, A., \& Nayar, K. R. (2021). COVID 19 and its mental health consequences. Journal of Mental Health, 30(1), 1-2. https://doi.org/10.1080/09638237.2020.1757052

2. United Nations. (2021). Secretary-General Calls Latest IPCC Climate Report 'Code Red for Humanity', Stressing 'Irrefutable' Evidence of Human Influence. https://www.un.org/press/en/2021/sgsm20847.doc.htm

3. Vuong, Q.-H. (2018). The (ir)rational consideration of the cost of science in transition economies. Nature Human Behaviour, 2(1), 5. https://doi.org/10.1038/s41562-017-0281-4

4. Vuong, Q.-H. (2019). Breaking barriers in publishing demands a proactive attitude. Nature Human Behaviour, 3(10), 1034. https://doi.org/10.1038/s41562-019-0667-6

5. Vuong, Q.-H. (2020). Reform retractions to make them more transparent. Nature, 582(7811), 149. https://doi.org/10.1038/d41586-020-01694-x

6. Van Huu, N., Hoang, V. Q., \& Ngoc, T. M. (2005) Central limit theorem for functional of jump Markov processes. Vietnam Journal of Mathematics, 33(4), 443-461.

7. Van Huu, N., \& Hoang, V. Q. (2007) On the martingale representation theorem and on approximate hedging a contingent claim in the minimum deviation square criterion. In: R. Jeltsch, T-T. Li \& I. H. Sloan (Eds.) Topics in Industrial and Applied Mathematics (pp. 134-151). Hackensack, New Jersey: World Scientific.

8. Vuong, Q. H., \& La, V.-P. (2019). bayesvl: Visually Learning the Graphical Structure of Bayesian Networks and Performing MCMC with "Stan" (SSRN Scholarly Paper ID 3469457). Social Science Research Network. https://papers.ssrn.com/abstract=3469457

9. Vuong, Q.-H. et al. (2020). Bayesian analysis for social data: A step-by-step protocol and interpretation. MethodsX, 7, 100924. https://doi.org/10.1016/j.mex.2020.100924

10. Nguyen, M.-H. (2021). Multifaceted interactions between urban humans and biodiversity-related concepts: A developing-country dataset. Data Intelligence, 1-24. https://doi.org/10.1162/dint_a_00110

11. Vuong, Q.-H. et al. (2021). A multinational dataset of game players' behaviors in a virtual world and environmental perceptions. Data Intelligence, 1-20. https://doi.org/10.1162/dint_a_00111

12. Vuong, Q.-H. et al. (2021). A Data Collection on Secondary School Students' STEM Performance and Reading Practices in an Emerging Country. Data Intelligence, 1-21. https://doi.org/10.1162/dint_a_00091

13. Vuong, Q.-H. et al. (2021). An Al-Enabled Approach in Analyzing Media Data: An Example from Data on COVID-19 News Coverage in Vietnam. Data, 6(7), 70. https://doi.org/10.3390/data6070070

14. Nguyen, M.-H., \& Le, T.-T. (2021). Bayesian Mindsponge Framework. In Scholarly Community Encyclopedia. Basel, Switzerland: MDPI AG.

15. Nguyen, M.-H. et al. (2021). Alice in Suicideland: Exploring the Suicidal Ideation Mechanism through the Sense of Connectedness and Help-Seeking Behaviors. International Journal of Environmental Research and Public Health, 18(7), 3681. https://doi.org/10.3390/ijerph18073681

16. Vuong, Q.-H., Nguyen, M.-H., \& Le, T.-T. (2021). A Mindsponge-Based Investigation into the PsychoReligious Mechanism Behind Suicide Attacks. Sciendo. https://doi.org/10.2478/9788366675599

17. Vuong, Q.-H. (2021). The semiconducting principle of monetary and environmental values exchange. Economics and Business Letters, 10(3), 284-290. https://doi.org/10.17811/ebl.10.3.2021.284-290 